Print ISSN: 2233-4165 / Online ISSN: 2233-5382

doi:http://dx.doi.org/10.13106/ijidb.2018.vol9.no11.93.

\title{
Effects of SM-sized Manufacturing Firm Management Performance: Control Effect of CEO Characteristics and Mediating Effect of Core Competence
}

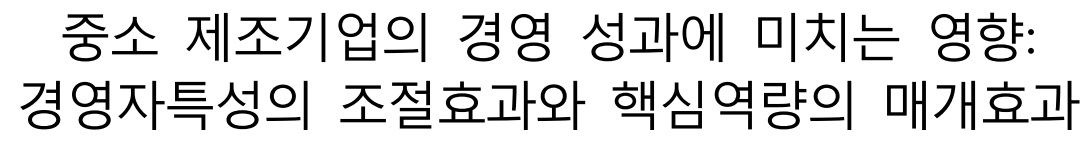

Young-Dong Roh(노영동)*, Sang-Beom Park(박상범)**

Received: October 15, 2018. Revised: November 04, 2018. Accepted: November 10, 2018.

\section{Abstract}

Purpose - For small and medium sized firms, CEO characteristics are main factor influencing firms' prosperity as well as performance. So it is quite natural that many people are interested in factors of CEO that matters. In this research, CEO characteristics in terms of capabilities and skill or special knowledge necessary to run the business are invested for manufacturing firms. Precedent studies reveal that CEO characteristics such as psychological factors including desire to succeed, tendency to take risks, personal factors including age, year of running business, and task related factors including managing capability, communication skills, network influence firm performance for manufacturing firms. However, these studies simply verify whether or not those factors affect firm's managing performance. This study, however, goes further to investigate how is the affecting process from CEO's capabilities and organization characteristics to firm's core competence, and from core competence to advantages, and from advantages to managing performance.

Research design, data, and methodology - We make a questionnaire and surveyed manufacturing firm CEO's in Gyeonggi-do area. General characteristics analysis, factor analysis, regression analysis, and control effect analysis was conducted. SPSS 2.0 Win, version was used.

Results - The CEO characteristics including basic capability, task capability, leadership, and organization characteristics affect core competence at the statistically significant level. And, core competence affect both price advantage and differentiation advantage at the significant level. Some unique finding is that while differentiation advantage affects both financial achievement and non-financial achievement, price advantage does not affect both financial and non-financial achievement. And firm characteristics mainly measured by CEO characteristics of skills has control effects on the trace from core competence to price advantage.

Conclusions - For small and medium sized firms CEO characteristics is the most important factor influencing firm's prosperity. For manufacturing firms, whether CEO has the skill or special knowledge to run the firm is critical factor. The study results show that CEO's for manufacturing firms put importance on price and price advantage which seems to be familiar to them. However, the price advantage does not influential to financial and non-financial achievement. This result suggests that small and medium sized manufacturing firms' CEO's should make effort to improve other aspects of advantages to be more competitive.

Keywords: Small and Medium-sized Firm, CEO Characteristics, Firm Characteristics, Core Competence, Management Performance.

JEL Classifications: D21, L23, L60, L89, M14.

\section{1. 서론}

중소기업이라 함은 상대적 개념이다. 여기서 상대적 개념이

* First Author, Ph.D student, School of Business Administration, Korea Aerospace University, Korea, E-mail: balhae22@naver.com

** Corresponding Author, Professor, School of Business Administration, Korea Aerospace University, Korea.

Tel: +82-2-300-0352, E-mail: psb@kau.ac.kr
라 함은 우리나라의 경우 대기업을 염두에 두거나 중소기업에 미치지 못하는 소규모 영세사업형태와 구분하기 위해 사용하 는 개념이라는 뜻이다. 현실적으로 부족한 자원과 자본, 낮은 기술력 상태에서 중화학공업위주의 수출주도형 경제개발을 추 구하려다 보니 특정 몇몇 기업에 자본과 기회가 집중돼 온 사 태가 벌어졌고 재벌이라는 형태의 기업군이 등장하고 우리경 제에서 막강한 영향력을 행사해 오고 있다. 이에 따라 중소기 업들은 상당 부분 대기업의 하청업체로 전락하여 명맥을 유지 
하여 오고 있기도 하다

2017년 기준 국내 중소기업의 수는 58만 518개로 전체 기 업체 수의 $99.2 \%$ 에 달하고 있으며, 특히 고용의 $90 \%$ 이상을 담당하고 있다. 우리나라의 경우 점유율로만 보았을 때 중소기 업이 국가산업의 근간이라고 할 수 있으며, 세계적으로 불고 있는 4차산업, 자동화, 정보화, 삶에 대한 새로운 가치관, 산업 패턴의 급격한 변화 등에 신속하고 적절히 대처해 낼 수 있는 주체가 중소기업이라고 볼 수 있다. 그러나 실제로는 생산규 모, 생산성, 임금수준, 자금력 등에서 대기업에 비해 상당수의 중소기업이 열악한 상태에 처해 있으며 현실적으로 우리나라 중소기업들은 상당수가 대기업의 하청업체 혹은 재하청업체 역할을 하거나 소상공인 수준에 머무르고 있다. 정책차원에서 도 이러한 점들을 인식하고 중소기업 육성을 지원하고 있으나 그 효과는 미미한 편이다.

이러한 상황 하에서 중소기업에 대한 관심은 자연스레 중소 기업의 경쟁력은 무엇인가 라는 질문에 모아지게 된다. 기업의 경쟁력은 다양한 측면과 차원에서 형성되고 유지되거나 향상 되어 간다고 볼 수 있다. 기술력이나 인적자산, 원가절감 노하 우, 탄탄한 판로 등 다양한 측면에서 경쟁력을 보유하게 된다. 최근에는 이러한 다양한 측면에서의 경쟁력과 관련하여 개별 차원의 강점이 발휘되는 경쟁력으로 이해하기 보다는 이러한 강점 혹은 강점들이 기업의 다른 요소나 차원과 결합하여 동 적인 경쟁력을 이루게 된다는 소위 말하는 핵심역량이 무엇인 가 라는 차원으로 접근하는 방식이 공감을 얻고 있다. 이러한 접근은 단순히 현재 상태에서의 경쟁력을 분석하는 데에서 머 무르지 않고 급변하는 산업경쟁 하에서 미래지향적 경쟁력을 유지해 나갈 수 있는 원천이 무엇일까 라는 동적인 관심에 대 한 답을 구하고자 하는 의도가 작용한다고 할 수 있다.

본 연구에서는 이러한 상황과 시각에서 중소기업의 핵심역 량에 대해 연구해 보고자 한다. 특히 우리나라 대다수 중소기 업이 안고 있는 소유경영의 형태에서 오너의 기술보유 여부, 리더십, 역량 등이 핵심역량에 미치는 영향을 파악해 보고자 한다. 중소기업의 경우 $\mathrm{CEO}$ 도 조직구성원의 일원으로서의 역 할을 하고 조직에 포함되지만 대부분의 경우 CEO는 소유자이 자 경영자이기 때문에 $\mathrm{CEO}$ 의 특성은 기업의 성과는 물론 존 망에 결정적 영향을 미칠 수 있다는 측면에서 접근되어야 한 다고 보기 때문이다(Lee \& Kim, 2003).

연구방법론으로는 전통적 노동 집약 산업으로 대표되는 경 기도 일대 제조업체를 대상으로 기업이 보유하고 있는 자원, 경영자의 핵심기술 보유 여부, 경영자 특성의 변수들이 어떻게 핵심역량을 구성하여 영향을 미치고 핵심역량이 다시 차별화 등 경쟁력에 영향을 미치는지 여부 그리고 이러한 경쟁력이 기업의 경영성과 및 조직성과에 영향을 미치는지 여부에 대하 여 실증적으로 분석하고자 한다. 그리하여 본 연구에서는 중소 제조기업 $\mathrm{CEO}$ 를 대상으로 설문조사를 실시하여 그 결과를 바 탕으로 실증분석을 하여 보고자 한다.

\section{2. 이론적 배경}

2.1. 중소기업

\subsection{1. 중소기업의 개념}

중소기업의 개념은 상대적이다. 즉, 대기업이나 매우 영세한
기업의 존재를 전제로 하여 중소기업의 개념이 부각된다. 대기 업은 물론 너무 영세한 기업은 중소기업의 범위에서 제외될 수 있는 것이다. 중소기업과 대기업을 구분하는 기준이 되는 지 표는 질적 지표와 양적 지표의 다른 방향에서 생각할 수 있다.

질적 지표로는 기업의 독립성, 시장지배 정도, 소유와 경영 의 분리 엽 및 정도, 경영자가 경영 전반을 주체적으로 관리할 수 있는 정도 등을 생각할 수 있다. 양적 지표로서는 종업원 수 - 자본금-매출액-자산의 크기 등을 거론한다. 이때 시장점 유율은 시장지배력을 나타내므로 질적 지표로 분류할 수도 있 는 동시에 양적 지표로 볼 수도 있다. 정량적 지표는 객관적이 고 확실하기 때문에 정책적용에 반영하기 수월하다. 그러나 양 적 지표에도 다양한 지표가 존재하기 때문에 이들 중 하나의 지표만을 선택하기가 어렵기 때문에 복수의 지표를 채택하여 사용하기도 하고, 산업에 따라 다양한 지표를 필요로 할 수 있 기 때문에 일률적으로 결정하기 어렵다. 더군다나 시대는 끊임 없이 변천하고 경제 역시 발전하므로 양적 지표를 일률적으로 정하고 고정시켜 놓을 수는 없다. 대기업과 중소기업은 지표에 의한 구분도 이와 같이 간단하지 않다. 다만, 중소기업기본법 등 규정에서는 지표로 이를 정하고 있다.

\section{2. 경영자원}

자원(resource)은 기업이 기업활동을 위해 보유하는 유형과 무형으로 정의되어지는 자산이자 힘이다(Kwan, 2006; Park, et al., 2008; Wernerfelt, 1984). 자원은 기업의 강점(strength)과 약점(weakness)이 될 수 있으며, 기업활동을 하는 동안 지속 적으로 존재한다. 경영자원에 관한 기존연구들은 기업의 자원 보유 정도에 중심을 두고 이루어져 왔는데, Wernerfelt(1984)는 기업의 자원으로 기술력, 고객 충성도, 생산 경험과 능력, $\mathrm{R \& D}$ 와 같은 연구능력 및 선도적인 기술력 등을 들고 있으며, 이러한 자원을 체계적으로 활용하여 기업자원으로 유지하고 활용하여야 한다고 하였다. Dierickx and Cool(1989)은 기업이 전략 수립시 핵심요소로 자원(브랜드 충성도)과 기술(기술 및 전문 지식)을 증가시키기 위해 광고비, 연구와 개발비 등 전략 적 지출의 적절한 선택이 필요하고, 인적 자원은 단순히 기본 적인 노동력을 제공받기 위한 것이 아닌 기업에 특정한 가치 와 기술로 기여하도록 하기 위하여 채용하고 기업이 필요한 특수한 기술 지식, 가치를 교육과 훈련을 통해 습득하도록 해 야 할 존재라 하였다. Collis and Montgomery(1995)는 기업의 무형적 자원으로 특정 브랜드, 브랜드 로열티, R\&D 능력, 기 술력, 노하우, 리더십 등이며, 기업역량으로는 기업 역사, 업 무 프로세스, 조직문화 등이고 자원과 역량을 동일한 차원에서 분류하기도 하였다. 그리고 Chang(2007)은 자원의 분류와 관 련하여 특별히 정해진 원칙은 없지만 유형자원(tangible resource), 무형자원(intangible resource), 인적자원(human resource)의 세 측면으로 나누어 볼 수 있으며, 인적자원의 경 우 유형의 자원으로 생각할 수 있지만, 기업활동 중에서 서비 스의 경우 종사자가 체득한 노하우, 기술, 지식, 의사결정능력 과 같은 눈에 보이지 않는 무형자산이며, 가장 중요한 경영자 원으로 보아야 하기 때문에 유형자원과는 차별되는 무형자원 의 주요 부분으로 보아야 한다고 보고 있다.

\section{3. 핵심역량}

핵심역량은 1990년대 이후 선진각국에서 각광받고 있는 경 
영 관련 혁신적 패러다임으로, 종전까지의 기업활동을 주도한 핵심역량들을 제대로 찾아내고 이들을 전사적 차원에서 유기 적으로 이용하는 동시에 기존 역량에 기술, 서비스 등을 추가 하여 기업이 새롭고 유연하며 다각적으로 성과를 낼 수 있도 록 하는 경영방식을 말한다. 지금까지 선진 기업들의 전략의 대부분은 자신의 핵심역량, 즉 기업의 근저에 대재한 지식의 총체, 기술 및 기술개발능력 등에 대한 깊이 있는 파악이나 이 해없이 단순히 산업환경의 변화에 따라 나타날 수 있는 기회 만을 포착하는 외부환경에 의존하는 다각화를 추구해왔다. 한 동안 각광을 받았던 리엔지니어링 이론 역시 단위기업의 생존 을 위한 단순한 전술로 볼 수 있으며 결국 단기적인 생산성 제고 효과는 거둘 수 있지만 오히려 미래 시장의 점유율은 위 축시키는 결과를 가져온 것으로 밝혀졌다. 그러나 핵심역량에 기한 경영은 기업의 미래가 성공적이기 위해서는 스스로의 한 계를 뛰어넘는 수준으로 미래의 위상을 설정한 뒤, 그 위상에 도달하기 위한 핵심역량을 설정하고 이를 달성할 노력을 경주 하여야 할 것이 필요하다고 주장한다. 기업의 핵심역량을 발굴 및 양성해 나름대로 기업고유의 문화와 경쟁전략을 수립하고 키워가는 것이라 볼 수 있다.

핵심역량(core capabilities)은 특별하거나(unique), 독특함 (distinctive), 모방의 어려움(difficult to imitate), 경쟁력(superior to competition), 자원배치 능력(resource deployment) 혹은 기 술(skills) 등 다양하게 정의되어 왔다(Leonard-Barton, 1992). 조직이론이나 경영 전략가들에 의한 역량(competence)은 조직 전체를 하나의 유기체로 보고 기업전략의 관점에서 경쟁력을 확보해 줄 수 있는 원천이며(Park, 2002), 자원준거관점에서의 핵심역량이란 과거부터 현재까지 기업을 이끌어 왔으며, 적절 하게 전환되거나 추가의 역량을 축적시키면서 미래 성장의 견 인차 역할을 할 수 있는 능력, 기술, 지식을 의미하는 것으로 사업 경쟁력의 기반이 될 수 있는 경쟁우위의 뿌리 역할을 한 다는 것이다(Kim, 2005). 이러한 역량은 기업의 다양한 행위를 설명하기 위해 폭넓게 활용되어 왔으나, 최근 역량(capability) 이 어떻게 기업성과에 기여하는가를 설명하는 동적역량 (dynamic capability) 관점에 의해 더욱 발전하고 있다(Choi, 2008; Makadok, 2001). 동적역량은 자원기반관점에서 파생된 이론으로서 변화하는 산업 환경에 적절히 대처하기 위해 기업 내부의 조직력과 제반 자원들(재무, 기술, 평판, 조직구조, 제 도 등), 그리고 각 부문별(functional) 기능을 적절하게 통합, 재구성하는 것을 말하고 더불어 이를 통하여 지속적 혁신을 도모할 수 있는 잠재적 능력을 의미한다고 본다(Kwan, 2010; Teece, Pisano, \& Shuen, 1997). Choi(2008)는 기업역량을 관 리역량, 기술역량, 산출물기반역량으로 구분함으로써 기업자원 과 기업역량을 명시적으로 구분하되, 자원을 단순히 보유하는 것이 중요한 것이 아니며 자원들이 상호작용을 하도록 하고 이렇게 창출된 기업역량이 조화되고, 적절배치, 레버리지 프로 세스, 역동적 작동을 통해 경쟁우위 확보를 가능케 한다고 하 였다. 핵심역량을 특정산업의 관점에서 바라보는 시각으로 Jeon(2011)은 외식기업의 경우 핵심역량은 이를 통해 기업이 경쟁사보다 나은 성과를 달성하기 위해 자원을 개발.조달.분배 및 조합할 수 있도록 해주는 역동적이고 비정형적인 메커니즘 이라고 보았다.

핵심역량의 구성요인에 대해서는 자원기반관점에서 Grant (1991), Mahoney(1995)는 물질적 자원, 재무적 자원, 인적자 원, 기술자원, 명성자원, 조직자원으로 선정했고, Hitt and Ireland(1986)는 일반관리, 생산운영, 기술, 연구개발, 마케팅,
재무관리, 인사관리, 공중 및 감독기관 관계로 구분하였다. 한 편, Son and Kim(2007)은 호텔기업의 경우 핵심역량의 하부 차원으로 마케팅관리능력, 인사관리능력, 상품개발능력, 서비 스생산관리능력, 조직관리능력, 재무/회계관리능력을 지적하고 있다. 중소제조기업의 경우, 기술적 자원, 마케팅자원, 관리자 원이 주요한 요인으로 판단된다.

\section{4. 경쟁우위}

경쟁우위는 단일 사업부 수준이든 기업 수준의전략이든 상 관없이 기업의 R\&D, 자산, 기업 브랜드 아이덴티티(identity)와 같은 특별한 가치를 가진 자원의 보유에 의해 형성된다 하였 다(Collis \& Montgomery, 1995). Porter(1980)는 경쟁우위를 위 한 전략 중 원가우위를 효율적이고 적극적인 생산설비 운영, 경험에 기한 비용절감, 원가 관리와 비용 최소화로 정의하고, 차별화우위는 디자인, 브랜드, 기술력, 조직능력, 판매망 등 제 품이나 서비스 관련 차별화시킬 수 있는 능력이라고 정의하였 다.

우선, 원가우위란 기업이 가격상의 우위를 확보하기 위해 비용을 줄이고 저가격의 제품을 소비자에게 공급하기 위해 노 력하는 것으로 기업이 시장을 점유하기 위하여 그들의 비용구 조를 개선함으로써 경쟁우위를 확보하는 것이며(Porter, 1980), 이는 효율적인 규모의 생산시설과 비용감소를 위한 적극적인 노력, 강력한 비용 통제, 그리고 R\&D, 서비스, 판매력, 광고 등의 분야에서 비용을 최소화하는 것이라고 하였다. Gupta (1987)는 원가우위 전략을 위해서는 재고관리, 운반 및 유통비 용을 절감하고 대량 생산의 이점을 살리도록 제품라인을 최소 화함으로써 효율성을 극대화에 중점을 두어야 한다고 주장하 였다. Grant(1991)는 원가우위를 확립하기 위해서는 생산공장 의 효율성, 뛰어난 기술력, 원자재의 저렴한 조달능력 또는 저 임금 노동력 확보기 필요하다고 보았다. 한편, 차별화 우위란 고객의 기호를 유발하기에 충분한 특이성을 제품에 나타내어 경쟁자의 제품과 식별토록 하는 동시에, 경쟁에 있어 유리한 지위를 점유하도록 하기 위해 쓰는 전략이며, 제품 및 서비스 차별화전략은 고객서비스나 제품 품질 등의 우위를 통해 고객 의 만족도를 높여 경쟁우위를 확보하려는 전략이라 하였다 (Park et al., 2004). 이는 기업이 경쟁기업과 차별화할 수 있 는 제품의 독특성이나 특별한 서비스를 제공하는 전략으로써 제품의 디자인이나 브랜드, 외형, 기술력 그리고 고객서비스 및 유통조직에서 타사제품보다 차별화된 측면을 추구하며, 이 러한 점을 선호하는 고객은 가격 등에 구애받지 않고 해당 제 품만을 구입하게 되며 브랜드로 인해 형성되는 이미지와 제품 의 유일성과 차별성 때문에 경쟁자의 참여가 어렵게 된다고 보았다(Kim, 2002). 그러나 차별화를 추구하는 기업은 경쟁사 의 원가경쟁력이 자사의 높은 가격을 상쇄시킬 수 있기 때문 에 차별화에 영향을 주지 않는 모든 영역에서 원가를 절감시 킴으로써 경쟁자와의 원가를 같게 하거나 비슷하게 해야 한다 고 지적하였다. 또한 Porter(1990)는 기업들 간에서 쉽게 복제 가 될 수 있고, 기업은 전형적으로 차별화우위를 바탕으로 하 기 때문에 원가우위와 차별화우위를 동시에 취하는 이중경쟁 우위(dual advantages)는 희박하다고 하지만, 비용과 차별화 사이에 교환이 불가능하므로 이들 간은 오히려 보안 (trade-ones)이 되어 경쟁전략 방법으로 산업 내에서 이를 동 시에 활용한다고 하였다(Ghemawat, 2009). 


\section{5. 경영성과}

기업의 경영성과는 크게 재무적 성과와 비재무적성과로 나 누어 볼 수 있는데, 재무적 성과에는 수익성, 성장성, 생산성, 총 매출액 등의 계량적 분석이 가능한 성과를 말하며 비재무 적 성과는 구성원들의 사기, 직무만족, 조직몰입 등의 계량적 분석이 어려운 성과를 비재무적성과라고 말한다(Park et al., 2011). 비재무적 성과는 사실 다양한 측면, 범위를 포함하게 되고 객관화하기 어려운 측면이 있으나 종합적이고 포괄적인 성과측정이 가능하다는 장점이 있다(Steers, 1975). Beard and Dess(1981)는 다차원적인 측면에서 기업성과를 측정하는 것이 필요하다고 하였으며, Venkatraman and Ramanujarn(1986)은 기업전략 관련 연구에서 경영성과 측정으로 재무측면의 성과, 조직측면의 성과를 포함한 비재무적 성과, 그리고 주관적 지표 로 조직 효과로 구분하여 다차원 구조로 성과를 측정하였다.

비재무적 성과로 고객만족(Fornell, 1992; Rust et al., 1993), 고객의 재구매율(Anderson et al., 1993), 시장점유율 (Rust \& Zahorik, 1993) 등으로 측정하고 있다. 또한 전통적으 로 사업성과가 회계용어로 간주되고(Conant, Mokwa, \& Varadarajan, 1990), ROI(return on investment), 순이익(net earing) 등 객관적 자료를 분석하는 형태로 측정되었지만, 많 은 연구들에서 재무성과 측정에 있어 주관적 성과(subjective performance) 혹은 인지적 성과(perceived performance) 등도 사용하고 있다고 하였다(Han \& Yoon, 2011). 이처럼 경영성과 는 다양한 연구관점에 따라 성과 측정이 되어져 왔다.

\section{3. 선행연구}

중소기업 관련 연구는 자료를 얻기가 쉽지 않은 점, 대기업 에 비해 상대적으로 관심이 적었던 점, 다양한 업종에 관여하 여 공통성을 찾기가 쉽지 않다는 점(Kwan \& Lee, 2009) 등에 서 연구가 활발하게 진행되어 오지는 않았다고 여겨진다. 그 중 주된 관심의 대상은 중소기업 최고경영자의 역할모델에 관 한 것과 중소기업의 경쟁력에 관한 부분이다. 특히 중소기업의 $\mathrm{CEO}$ 의 역량은 중소기업의 존망을 좌우하는 경우가 많기 때문 에 관심이 집중되는 부분의 하나이다. 즉 중소기업의 경우 $\mathrm{CEO}$ 의 역량이 중소기업의 존망에 직접 영향을 미친다고 보는 시각이 대부분인 것이다.

본 연구는 중소기업 그중에서도 제조업의 경우 $\mathrm{CEO}$ 의 역 량과 핵심역량 그리고 차별화와 경영성과 간의 영향관계를 살 펴보고자 하는 것이다. 이에 따라 선행연구 관련하여 중소기업 및 중소기업 CEO에 관한 선행연구 및 핵심역량과 관련한 선 행연구들을 중점적으로 분석해 본다.

Park and Lee(2011)은 중소기업 최고경영자의 역량모델 개 발에서 중소기업 최고경영자의 역량모델을 개발하고자 Lucia \& Lepsinger(1999)가 개발한 새로운 역량모델개발 방법론 (Starting from Scratch)을 기초로 한 연구를 수행하여 도출된 43개 역량에 대한 타당성 검증을 통해 기본역량, 직무역량, 리 더역량 등 3 개의 역량 영역과 개인효과성, 기회인식, 전문지 식, 관계형성, 사업관리, 리더십, 인적자원관리 등의 7 개 역량 군으로 구조화하여 중소기업 최고경영자 역량모델을 제시하였 으며, 중요도 설문조사 결과 이들 중 중요도 수치 6.0(중요함) 이상으로 나타난 역량은 ‘위기관리', '영향력', ‘사업에 대한 열
정', ‘윤리의식', ‘커뮤니케이션’, ‘긍정적 사고', ‘구체적 목표 및 비전제시’ 등을 포함한 18 개 역량이란 점을 보고하였다(Park \& Lee, 2011).

Park(2005)은 영남지역 중소기업을 대상으로 최고경영자의 특성과 경영성과와의 영향관계 연구에서 최고경영자의 연령, 설립역사 등에서 형성될 수 있는 심리적 특성과 의사소통 등 역량특성은 경영성과에 긍정적 영향을 미치는 것으로 나타나 고 있다는 결과를 보고하고 있다. 또한 Lee and Kim(2003)은 중소기업의 기술보유, 경영자특성, 조직구조가 재무적 성과에 미치는 영향에 대한 연구에서 경영자특성과 조직구조는 재무 적 성과에 통계적으로 유의한 영향을 미치지 않는 반면, 기술 능력은 재무적 성과에 유의한 영향을 미치는 것을 발견하였다.

$\mathrm{Kim}(2002)$ 은 비상장, 비등록 중소기업의 재무레버리지 결정 에 관한 연구에서 기존의 변수 외에 중소기업 고유요인으로 경영자위험과 업력을 포함시켰으며, 연구결과 중소기업 경우 재무레버리지 사용에 있어서 유의적인 영향 관계에 있는 요인 들은 담보가치, 성장성, 업종, 기업크기, 수익성, 그리고 경영 자위험의 여섯 가지로 나타났음을 보고하고 있다. 추가로 담보 로 제공할 수 있는 고정자산의 비중이 크며 성장 정도가 크고 기업규모가 큰 제조업체의 경우 그렇지 않은 기업에 비하여 더 큰 부채를 사용하는 것으로 나타났으며 수익성이 높아 사 내유보를 많이 한 기업, 현금흐름이 불안정하여 경영자의 통제 권에 대한 위험이 높은 기업은 부채를 적게 사용하는 것으로 나타났다고 설명하고 있다.

Jung and Yang(2009)은 한 - 중 중소기업의 경우 네트워킹 정도가 지각된 기업성과에 영향을 미치는지 여부에 대한 실증 적 비교분석에서 사회적 자본의 핵심요소인 네트워크 및 네트 워킹 활동 구성요소들이 신생 사업의 생존과 성장 사업의 성 과에 어떠한 영향을 미치는지 살펴본 결과, 기존의 기업들의 경우 기업의 통제 하에 있지 않은 외부자원에 대한 효율적 접 근-활용능력 여부가 중소기업의 성과와 유의한 관계에 있다 는 결과를 보여주고 있다. 그러나 신생기업의 경우는 차이가 있을 수 있다는 전제하에, 한국기업의 경우 사업이 성장시 네 트워킹 활동이 기업성과에 더 유의한 영향을 미치는 반면 중 국의 경우 신생 사업의 경우 네트워킹 활동이 기업성과에 더 유의한 영향을 미친다는 결과를 보이고 있다.

Son and $\mathrm{Kim}(2007)$ 은 호텔산업에서 핵심역량과 경쟁전략 사이의 적합성이 경영성과에 미치는 영향연구에서 호텔기업의 핵심역량 수립, 실행 및 경영성과를 통한 적합성을 규명하였 다. 연구결과 호텔기업의 핵심역량유형과 비재무적 경영성과 간의 관계에 대한 가설은 통계적으로 유의하지는 않았지만, 마 케팅능력, 인사관리능력, 상품개발능력 요인은 양(+)의 긍정적 영향을 미치는 것으로 나타났으며 차별화 전략을 추구하는 호 텔기업에는 인사관리능력, 마케팅능력, 상품개발능력, 조직관 리 능력이 양(+)의 영향을 미치는 것으로 나타나고 있고 보고 하고 있다.

Kang and Lee(2012)은 기업가정신 및 핵심역량이 경영성과 에 미치는 영향에 대한 연구 중 환경 불확실성의 조절효과 분 석에서 기업가정신과 마케팅 측면의 경쟁력은 기업의 경영성 과 향상에 모두 유의한 영향을 주는 것으로 나타났다. 반면, 기술혁신 역량은 통계적으로 유의한 영향을 미치지 못하고 있 음을 확인하였다.

이상의 연구들을 종합하여 정리해 보자면, 중소기업 $\mathrm{CEO}$ 의 역량은 기업의 핵심역량에 영향을 미치며(Son \& Kim, 2007; Park \& Lee, 2011; Kang \& Lee, 2012), 기업의 자본, 연령, 
환경 등 특성에 따라 다른 경영특성을 보인다(Kim, 2002; Choi \& Kim, 2005; Jung \& Yang, 2009; Son \& Kim, 2007; Kang \& Lee, 2012)는 결과로 요약 및 정리될 수 있다.

\section{4. 연구설계}

\section{1. 연구모형}

본 연구에서는 중소제조기업의 경영자의 역량과 특성이 회사 의 흥망에 결정적 역할을 할 것이라는 가정 하에 경영자의 역 량 및 특성이 어떻게 회사의 핵심역량을 구성하고 영향을 미치 며 핵심역량은 다시 회사의 경쟁력에 영향을 미치는지 나아가 그 결과로서 회사의 성과로 이어지는지 하는 점에 대해 분석해 보고자 하며 이에 따라 다음과 같은 연구모형을 구축한다.

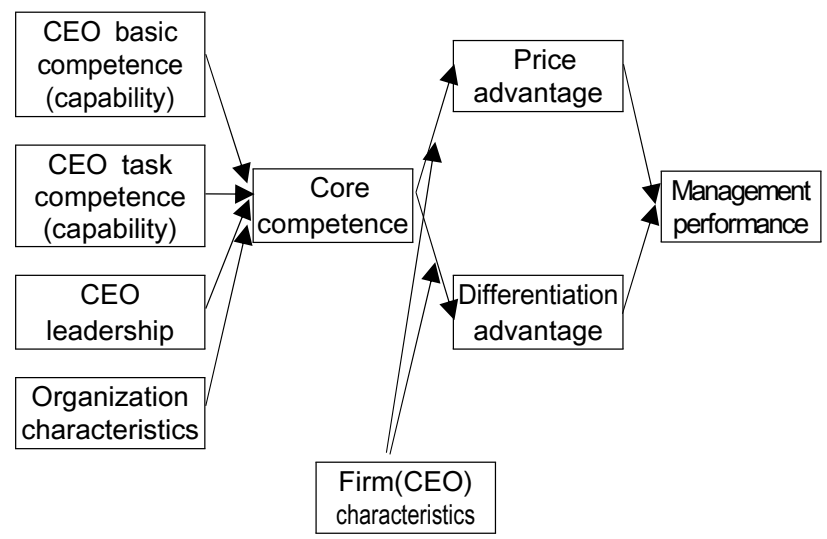

Figure 1: Research Model

위 연구모형에서 중소제조기업의 가장 중요한 경영자원으로 경영자의 역량과 업무능력, 회사의 조직구조를 들고 있으며 이 들 자원이 핵심역량의 구성에 작용하고 영향을 미친다고 보며 이때 기업특성이 조절효과를 갖는다고 예측하며, 핵심역량은 다 시 경쟁력에 영향을 미치고 다시 성과를 좌우한다고 가정한다 $<$ Figure $1>$.

이러한 연구의 목적은 경영자원이 경영성과에 영향을 미친 다는 연구결과들(Park, 2005; Lee \& Kim, 2003)을 바탕으로 경영자원이 어떠한 과정을 거쳐서 경영성과로 이어지는지에 대한 분석을 하고자 하는 것이다. 이러한 분석결과는 개별 경 영자원들이 경영성과에 미치는 영향들을 종합함은 물론 어떠 한 방식으로 종합화되고 역동성을 발휘하게 되어 경쟁력을 높 이는지에 대한 이해를 높일 것이다.

\section{2. 가설 설정}

\subsection{1. 경영자원과 핵심역량과의 관계}

기업의 태동에는 나름대로의 경쟁력을 갖추고 있다는 확신 이 있을 것이며 그것이 시장에서 인정됐을 때 성장을 구가할 수 있을 것이다. 기업의 경쟁력은 다양한 원천에 기인할 수 있 을 것이며, 예컨대, 원가절감 능력, 기술력, 경영능력, 소비자 니즈에 맞는 신상품, 디자인 등 다양할 것이다. 이러한 경쟁력
을 하나로 묶어서 보는 자원준거관점은 다양한 경쟁력을 분석 하거나 경쟁력 원천이 하나 이상일 경우 원천경쟁력의 조합과 조화, 그 과정, 시너지효과 등을 살펴보는데 제약을 가질 수밖 에 없다(Kwan, 2006). 특히 1990년대 이후 기업의 자원과 역 량을 구분해서 보고자 하는 움직임이 있어왔다. Grant(1991)는 경영자원과 역량을 서로 다른 개념으로 보았으며, 기업의 경영 자원이 역량의 원천이 되나 단순히 경영자원을 모은다고 역량 이 되는 것은 아닐 수 있다는 점을 강조하였다(Choi, 2008).

이러한 논의를 바탕으로 중소기업의 경우를 분석해 보는데 있어, 가장 큰 영향요인이 $\mathrm{CEO}$ 의 역량, 업무능력, 특성을 기 초로 하며 여기에 회사의 조직구조 그리고 특성을 경영자원으 로 보며 이들 경영자원이 핵심역량에 미치는 영향을 분석해 보기 위하여 다음과 같은 가설을 설정한다.

가설1: 중소제조기업의 $\mathrm{CEO}$ 의 역량은 핵심역량에 영향을 미칠 것이다.

가설1-1: 중소제조기업의 $\mathrm{CEO}$ 의 기본역량은 핵심역량에 영향을 미칠 것이다.

가설1-2: 중소제조기업의 $\mathrm{CEO}$ 의 업무역량은 핵심역량에 영향을 미칠 것이다.

가설1-3: 중소제조기업의 $\mathrm{CEO}$ 의 리더십은 핵심역량에 영향을 미칠 것이다.

가설1-4: 중소제조기업의 조직특성은 핵심역량에 영향을 미칠 것이다.

\subsection{2 핵심역량과 경쟁우위와의 관계}

기업의 핵심역량과 경쟁우위 관련 연구들에 의하면 역량은 기업의 전략수립과 밀접한 관계에 놓여 있으며(Choo et al., 2009), 특히 핵심역량은 전략수립의 근간이 된다고 보고 있다. 경쟁우위에는 물류역량, 생산역량, 마케팅- 판매역량서비스역 량, 하부조직역량 등이 있으며 이들 역량은 각각 원가우위, 차 별화우위에 영향을 미치게 된다(Nam \& Lee, 2009). 본 연구 에서는 회사의 핵심역량이 경쟁우위에 영향을 미칠 것이라 보 며, 중소기업의 경우 가격우위 혹은 차별화우위 또는 원가우위 와 차별화우위를 동시에 갖게 된다고 보고 다음과 같은 가설 을 설정한다.

가설2: 중소제조기업의 핵심역량은 경쟁우위에 영향을 미칠 것이다

가설2-1: 중소제조기업의 핵심역량은 가격우위에 영향을 미칠 것이다

가설2-1: 중소제조기업의 핵심역량은 차별화우위에 영향을 미칠 것이다

\subsection{3. 기업특성의 조절효과}

본 연구는 중소제조기업의 경우에 초점을 맞추고 있다. 중 소제조기업의 경우 기업특성 가운데 가장 중요한 점은 $\mathrm{CEO}$ 가 사업 관련 전문기술과 지식을 가지고 있는지 여부이다(Lee \& $\mathrm{Kim}, 2003)$. 중소기업의 경우 전문경영인을 초빙하기 어렵고 기술력을 바탕으로 창업을 하는 경우가 많으며, 해당 기술력이 곧 기업의 경쟁력의 근간이 되는 경우가 많기 때문이다. 이러 한 특성은 기업의 핵심역량 그리고 산업에 대한 깊이 있는 이 해를 기반으로 하여 차별화전략을 수립하고 추진해 나갈 것이 라 판단된다. 이에 따라 다음과 같은 가설을 설정한다. 
가설3: 기업특성은 핵심역량이 경쟁우위에 영향을 미치는 과정에 조절효과를 갖는다.

가설3-1: 기업특성은 핵심역량이 가격우위에 영향을 미치 는 과정에 조절효과를 갖는다.

가설3-2: 기업특성은 핵심역량이 차별화우위에 영향을 미 치는 과정에 조절효과를 갖는다.

\subsection{4. 경쟁우위와 경영성과와의 관계}

경쟁우위는 경영성과로 이어질 것이라 볼 수 있는데(Jung \& Eom, 2010; Noh, 2012), 경영성과를 측정함에 있어서는 크 게 재무적 성과와 비재무적 성과로 구분한다. 재무적 성과는 순이익의 증가, 이익률, 수익률 등 다양한 측면에서 분석해 볼 수 있으며, 비재무적 성과와 관련하여서는 회사 관련 종업원, 고객, 내부프로세스 측면에서 살펴보는 것이 의미가 있다고 판 단된다.

가설4: 중소제조기업의 경쟁우위는 경영성과에 영향을 미칠 것이다.

가설4-1: 중소제조기업의 가격우위는 재무적 성과에 영향 을 미칠 것이다.

가설4-2: 중소제조기업의 가격우위는 비재무적 성과에 영 향을 미칠 것이다.

가설4-3: 중소제조기업의 차별화우위는 재무성과에 영향을 미칠 것이다.

가설4-4: 중소제조기업의 차별화우위는 비재무성과에 영향 을 미칠 것이다.

\section{3. 변수의 조작적 정의 및 측정}

\subsection{1. 경영자원/CEO역량}

중소제조기업의 경우 $\mathrm{CEO}$ 의 역량이 가장 큰 자원이 될 것 이다(Lee \& Kim, 2003). CEO의 역량을 하나의 개념으로 묶어 표현하기에는 어려움이 있으나, 연구자들이 공통적으로 제시하 는 핵심은 어떤 직무에서 성공하거나 남들보다 나은 성과와 관련된 특성이라고 본다(Park \& Lee, 2011). 특히 중소기업 최고경영자의 역량모델을 개발한 Park and Lee(2011)이 제안 하고 있는 기본역량, 직무역량, 리더역량을 $\mathrm{CEO}$ 역량의 하위변 인으로 보고자 한다. 기본역량에는 겸손, 열정 등 개인 성향적 측면과 기회포착 및 시장파악 등 사업적 측면이 반영되어 있 다(Park, 2005; Lee \& Kim, 2003). 직무역량에는 정보인식, 사 업상 필요한 관계형성 능력, 사업관리 능력을 포함한다(Park, 2005; Lee \& Kim, 2003). 리더역량의 구성부분으로는 리더십 과 조직관리 능력을 주요 역량으로 본다(Gwak, 2016). 기본역 량에는 나는 겸손하며 솔선수범하는 편이다, '나는 윤리의식이 확고한 편이다, 나는 지속적인 자기개발을 한다, 나는 사업에 열정이 있다'의 4 개 문항으로 구성되도록 하였다. 직무역량으 로는 나는 시장변화 및 환경변화에 대처하는 능력이 있다, 나 는 전문지식과 기술을 보유하고 있다, 나는 사업과 관련한 사 람들과 관계형성을 잘하는 편이다, 나는 회사 관리 능력이 있 다, 나는 중소기업 정택을 잘 활용하는 편이다의 5 개 문항으 로 측정하였다. 리더역량으로는 나는 회사에서 적절한 권한과 영향력을 행사한다, 나는 종업원의 의사를 주의깊게 경청한다,
나는 종업원을 위한 방안에 대해 연구한다의 3 개 문항을 포함 한다.

\subsection{2. 조직특성}

중소제조기업의 조직특성으로는 대기업이의 경우처럼 정밀 하게 조직되어 있거나 체계적인 교육훈련 프로그램을 구비하 고 있지 않은 경우가 대부분일 것이며, 직원의 이직과 신규진 입이 상대적으로 빈번한 경우가 많아 직원들 간의 유대나 뚜 렷한 조직문화나 전통을 형성하고 있는 경우도 많지 않을 수 있다. 그러나 본 연구에서 살펴보고자 하는 측면은 중소제조업 에서 조직 내에서 의사결정권 등 권한 이임 정도, 구성원의 업 무 관련 의사개진의 자율성 정도 구성원간의 존중, 자기개발 기회 부여 여부 등 조직문화 혹은 조직특성이다. 이러한 특성 은 상대적으로 작은 규모의 기업에서 신속한 의사결정, 다양한 의사와 견해 취합, 자기개발을 통한 직무능력 향상이 가져올 수 있는 생산성 향상, 구성원의 업무 및 조직만족도 증가에 따 른 이직률 저하와 생산성 증가 등의 효과를 거둘 수 있을 것 이기 때문이다(Kwon \& Lee, 2018). 본 연구에서는 Jung (2008), Shin(2008)의 연구결과를 기초로 본 연구목적에 적합 하도록 인간존중적 조직특성, 기술전수지향적 조직특성 및 $\mathrm{CEO}$ 의 부재시 정상적 업무수행 가능 정도를 설문내용으로 삼 고 있다.

\subsection{3. 핵심역량}

제조업의 기업활동은 크게 생산, 판매, 수익확보 그리고 관 리로 구성되어 있을 것이다. 이러한 측면에서 중소제조기업의 핵심역량을 구성해 보자면, 우선 생산과 관련하여 기술력을 기 초로 할 것이며, 여기에 시설, 원료 및 재료를 적절한 가격과 시간에 조달할 수 있는 능력, 직원역량이 포함될 것이다. 판매 와 관련하여서는 마케팅능력, 직원의 서비스 역량, 광고홍보 역량, 거래처 확보 및 유지능력이 주요 요인일 것이다. 수익확 보 및 관리 차원에서는 재무회계 능력, 인사관리 능력, 조직관 리 능력이 필요하며 나아가 새로운 제품이나 서비스를 개발해 낼 수 있는 역량, 조직효율성 및 유연성 제고 능력이 될 것이 다(Jeon, 2011; Son \& Kim, 2007). 핵심역량에서 가장 중요한 측면은 이러한 역량들을 적절히 조화 배치하고 작동하도록 하 여 시너지효과를 창출해 내는 것이다(Choi, 2008). 이러한 측 면에서 본 연구에서는 중소제조업의 핵심역량을 생산, 판매, 관리능력과 이를 조화롭게 활용하여 작동하게 할 수 있는 역 량이라고 개념 정의하고자 한다.

이에 따라 중소제조업의 핵심역량으로 제품에 대하여 다른 경쟁업체에서 모방하기 어려운 기술력이 있다, 신제품 개발 능 력이 있다, 종업원의 역량이 우수하다, 충분한 거래처가 확보 되어 있다, 마케팅 노하우를 가지고 있다, 지속가능한 유통망 을 확보하고 있다의 6 개 문항으로 설문을 구성하였다.

\subsection{4. 기업특성}

중소제조기업의 경우 $\mathrm{CEO}$ 가 해당 분야 전문지식 혹은 기 술보유 여부는 직접적으로 재무적 성과에 영향을 미치며(Lee \& Kim, 2003), 경쟁우위의 원천이 될 수 있다(Kwon \& Lee, 2009). 즉 기업의 중요한 전략적 결정에 있어 중요한 역할을 하게 된다는 의미이다. 이에 따라 기업특성 중에서 $\mathrm{CEO}$ 의 전 문지식 혹은 해당 기술을 보유하고 있는지 여부가 미치는 영 
향에 대해 분석해 보고자 한다.

\subsection{5. 경쟁우위}

중소제조기업의 경쟁우위는 크게 2가지 차원으로 구분해 볼 수 있다. 하나는 원가절감 등을 통하여 구축할 수 있는 가격경 쟁력이며(Porter, 1980; Gupta, 1987; Grant, 1991), 다른 하나 는 기술력, 고객서비스, 마케팅능력, 유통조직 등을 통하여 구 가할 수 있는 차별화 우위이다(Park et al., 2004; Kim, 2002).

본 연구에서는 중소제조기업이 추구할 수 있는 경쟁우위로 가격우위와 차별화우위로 보고, 우리회사는 적정재고 수준을 유지한다, 우리화사는 원가절감을 위해 노력한다, 우리회사는 생산공장 및 시설확충에 힘을 쏟는다, 우리회사는 지속적으로 신제품 및 고객서비스를 개발한다, 우리회사는 광고 및 홍보활 동을 강화한다, 우리회사는 거래처 관리에 치중한다의 6 개 문 항을 설정하여 측정한다.

\subsection{6. 경영성과}

경영성과는 재무적 성과와 비재무적 성과 모두를 포함하여 측정한다. 재무적 성과는 수익성 향상, 영업이익 증가, 원활한 현금흐름으로 측정하며, 비재무적 성과로는 고객의 증가, 시장 점유율 향상 그리고 내부적 성과로 업무프로세스 표준화 향상, 직윙만족도 상승, 사내 정보공유 증가 등으로 측정한다.

\section{4. 설문조사}

본 연구는 중소제조기업에서 $\mathrm{CEO}$ 의 역량에 대한 연구이며 이를 위하여 경기도 지역을 중심으로 중소제조기업 $\mathrm{CEO}$ 들을 대상으로 2018년 7월부터 8월에 걸쳐 설문조사를 실시하였다. 설문지는 총 250 부를 배포하여 237 부를 회수하였으며, 그중 불성실한 기재, 식별하기 힘든 기재가 있어 확인하기 어려운 설문지 9부를 제외하고 227 부를 분석 대상으로 하였다.

\section{5. 통계분석}

\section{1. 인구통계학적 분석}

설문 응답자들의 일반적 특성은 다음 표에 요약되어 있다. 중소제조기업의 경우 응답한 $\mathrm{CEO}$ 의 전부가 남성이었으며, 직 접 설립한 경우가 $74 \%$ 에 달하고 있다. 855 이상이 직장경험이 있어서 직장생활을 하다가 독립하여 창업을 한 경우로 분석된 다. 연령, 경영연수, 종업원 수는 <Table 1>에 요약되어 있다.

Table 1: General Characteristics

\begin{tabular}{|c|c|}
\hline Construct & Components \\
\hline Sex & male 228 (100\%) \\
\hline Founded & founded 167(73.6\%), Not-founded 60(26.4\%) \\
\hline Job experience & yes 195(85.9\%), no 32(14.1\%) \\
\hline Age & $\begin{array}{c}\text { less than 30대: 0, 30's: 16(7\%), 40's: 89(39\%), } \\
\text { 50's: 87(38.2\%), 60 and more: 36(15.8\%) }\end{array}$ \\
\hline Year of & $\begin{array}{c}\text { less than 1 year 0, 1-2: 5(2.2\%), 2-5: 32(14\%), } \\
\text { 5-10: 59(25.9\%), 10-20: } 112(49.1 \%), \\
\text { management than 20: 20(8.8\%) }\end{array}$ \\
\hline No. of & $\begin{array}{c}\text { less than 10: } 23(10.1 \%), 10-20: 74(32.5 \%), \\
21-50: 64(28.1 \%), 51-100: 45(19.7 \%), \\
\text { more than 100: } 22(9.6 \%)\end{array}$ \\
\hline
\end{tabular}

\section{2. 요인분석}

다음 <Table 2>는 요인분석 결과이다.

Table 2: Summary of Factor Analysis

\begin{tabular}{|c|c|c|c|c|c|c|}
\hline Construct & $\begin{array}{l}\text { Item } \\
\text { label }\end{array}$ & $\begin{array}{l}\text { Eigen } \\
\text { value }\end{array}$ & $\begin{array}{l}\text { Factor } \\
\text { loading }\end{array}$ & \begin{tabular}{|c|}
$\begin{array}{c}\text { Item to } \\
\text { total } \\
\text { correlation }\end{array}$ \\
\end{tabular} & $\begin{array}{c}\text { Cronbach's } \\
\text { alpha }\end{array}$ & $\begin{array}{l}\text { Variance } \\
\text { explained }\end{array}$ \\
\hline $\begin{array}{c}\text { Basic } \\
\text { competency } \\
\text { (capability) }\end{array}$ & $\begin{array}{l}\text { Q1_1 } \\
\text { Q1_2 } \\
\text { Q1_3 } \\
\text { Q1_4 }\end{array}$ & 3.034 & $\begin{array}{l}0.784 \\
0.802 \\
0.573 \\
0.777\end{array}$ & $\begin{array}{l}0.712 \\
0.756 \\
0.509 \\
0.698\end{array}$ & 0.782 & 27.580 \\
\hline $\begin{array}{c}\text { Task } \\
\text { competency } \\
\text { (capability) }\end{array}$ & $\begin{array}{l}\text { Q2_1 } \\
\text { Q2_2 } \\
\text { Q2_3 } \\
\text { Q2_4 } \\
\text { Q2_5 }\end{array}$ & 2.982 & $\begin{array}{l}0.763 \\
0.629 \\
0.811 \\
0.603 \\
0.825 \\
\end{array}$ & $\begin{array}{l}0.701 \\
0.587 \\
0.745 \\
0.517 \\
0.755\end{array}$ & 0.883 & 27.109 \\
\hline Leadership & $\begin{array}{l}\text { Q3_1 } \\
\text { Q3_2 } \\
\text { Q3_3 } \\
\end{array}$ & 1.636 & \begin{tabular}{|l|}
0.614 \\
0.471 \\
0.577 \\
\end{tabular} & $\begin{array}{l}0.563 \\
0.421 \\
0.512 \\
\end{array}$ & 0.703 & 14.874 \\
\hline $\begin{array}{c}\text { Organization } \\
\text { characteristics }\end{array}$ & $\begin{array}{l}\text { Q4_1 } \\
\text { Q4_2 }\end{array}$ & 1.458 & $\begin{array}{l}0.729 \\
0.727 \\
\end{array}$ & $\begin{array}{l}0.699 \\
0.701 \\
\end{array}$ & 0.854 & 72.885 \\
\hline $\begin{array}{c}\text { Core } \\
\text { competency }\end{array}$ & $\begin{array}{l}\text { Q5_1 } \\
\text { Q5_2 } \\
\text { Q5_3 } \\
\text { Q5_4 } \\
\text { Q5_5 } \\
\text { Q5_6 }\end{array}$ & 3.489 & $\begin{array}{l}0.594 \\
0.529 \\
0.634 \\
0.616 \\
0.672 \\
0.444 \\
\end{array}$ & $\begin{array}{l}0.521 \\
0.479 \\
0.597 \\
0.523 \\
0.601 \\
0.411\end{array}$ & 0.818 & 58.156 \\
\hline $\begin{array}{c}\text { Price } \\
\text { advantage }\end{array}$ & $\begin{array}{l}\text { Q6_1 } \\
\text { Q6_2 } \\
\text { Q6_3 }\end{array}$ & 1.565 & \begin{tabular}{|l|}
0.568 \\
0.610 \\
0.587 \\
\end{tabular} & $\begin{array}{l}0.521 \\
0.578 \\
0.501\end{array}$ & 0.702 & 52.172 \\
\hline $\begin{array}{c}\text { Differentiation } \\
\text { advantage }\end{array}$ & $\begin{array}{l}\text { Q6_4 } \\
\text { Q6_5 } \\
\text { Q6_6 } \\
\end{array}$ & 1.725 & \begin{tabular}{|l|}
0.773 \\
0.807 \\
0.545 \\
\end{tabular} & $\begin{array}{l}0.703 \\
0.743 \\
0.512 \\
\end{array}$ & 0.712 & 57.490 \\
\hline & $\begin{array}{l}\text { Q7_1 } \\
\text { Q7_2 } \\
\text { Q7_3 } \\
\end{array}$ & 2.141 & \begin{tabular}{|l|}
0.720 \\
0.772 \\
0.649 \\
\end{tabular} & $\begin{array}{l}0.678 \\
0.710 \\
0.611 \\
\end{array}$ & 0.795 & 71.370 \\
\hline $\begin{array}{l}\text { Management } \\
\text { performance }\end{array}$ & $\begin{array}{l}\text { Q7_4 } \\
\text { Q7_5 } \\
\text { Q7_6 } \\
\text { Q7_7 } \\
\text { Q7_8 }\end{array}$ & 5.244 & \begin{tabular}{|l}
0.747 \\
0.529 \\
0.803 \\
0.675 \\
0.757
\end{tabular} & $\begin{array}{l}0.701 \\
0.498 \\
0.765 \\
0.610 \\
0.702\end{array}$ & 0.852 & 71.932 \\
\hline
\end{tabular}

위 표에서 신뢰도를 나타내는 크롱박 알파값이 모두 0.7 이 상의 값을 보이고 있어 신뢰도에 문제가 없다고 판단한다. $\mathrm{CEO}$ 역량은 기본역량, 직무역량 그리고 리더십으로 수렴하고 있으며, 조직특성 역시 하나의 요인으로 묶여지고 있다. 기업 의 핵심역량을 신제품개발 역량, 종업원역량, 거래선 확보역량 등으로 구분하여 설문구성을 하였으나 하나의 요인으로 추출 되고 있다. 경쟁우위 관련 가격우위와 차별화우위로 구분되어 요인분석되고 있으며, 경영성과도 재무적 성과와 비재무적 성 과로 수렴되고 있다.

\section{3. 회귀분석}

회귀분석은 중소제조업 $\mathrm{CEO}$ 의 역량, 조직특성이 핵심역량 에 미치는 영향 여부, 핵심역량이 경쟁우위에 영향을 미치는지 
여부, 그리고 경쟁우위가 경영성과에 영향을 미치는지 여부를 분석하기 위하여 실시되었다. 이와 같은 목적의 회귀분석 결과 는 <Table $3>$ 에 요약되어 있다.

<Table 3>에서 중소제조업 $\mathrm{CEO}$ 의 기본역량, 직무역량, 리 더십 그리고 조직특성은 모두 기업의 핵심역량에 통계적으로 유의한 수준에서 양(+)의 영향을 미치고 있는 것으로 나타나고 있다. 이러한 결과는 Seo and Lee(2012)의 연구결과와 일치하 며, 이러한 결과에 대해서 경영자원과 핵심역량은 차별화된 개 념으로 보고 있다.

다음으로 핵심역량은 가격우위와 차별화우위에 모두 양(+) 의 영향을 유의수준에서 미치고 있다는 것을 알 수 있다. 이 결과 역시 Seo and Lee(2011), Seo and Lee(2012)의 연구결 과와 유사하다. 가격우위가 재무성과에 미치는 영향과 관련하 여 사회과학에서 일반적으로 유의성 여부를 판정하는 0.05 를 기준으로 할 때 유의한 영향을 미치지 않는다는 것을 알 수 있다. 또한 가격우위는 비재무적 성과에도 영향을 미치지 않는
다는 점을 볼 수 있다. 이에 비하여 차별화우위는 재무적 성과 와 비재무적 성과 모두에게 유의한 영향을 미치는 것으로 나 타나고 있다.

기업 및 경영자특성이 핵심역량에 미치는 영향 그리고 핵심 역량이 경쟁우위 전략에 미치는 영향에 대한 분석은 기업 및 경영자특성이 경쟁우위에 미치는 과정에 있어서 핵심역량이 매개효과를 갖는지 여부를 검증하는 것과 마찬가지라고 볼 수 있다. 그리하여 기업 및 경영자특성이 경쟁우위에 영향을 미치 는 과정에 핵심역량이 매개효과를 갖는지 여부를 분석해 보았 으며 그 결과는 다음 표에 정리되어 있다. 매개효과 여부에 대 한 판정은 첫째, 독립변수가 매개변수에 유의한 영향을 미치 고, 둘째, 독립변수가 종속변수에 유의한 영향을 미치며, 셋째, 독립변수와 매개변수가 종속변수에 유의한 영향을 미치며, 둘 째 단계의 독립변수의 회귀분석 계수가 셋째 단계의 독립변수 의 회귀분석 계수 보다 클 경우 매개효과가 있다고 판정한다 (Song, 2014).

Table 3: Summary of Regression Analysis

\begin{tabular}{|c|c|c|c|c|c|c|}
\hline Independent Variable & Dependent Variable & Std. Error & $\beta$ & t- value & significance & $\begin{array}{c}\text { Statistics } \\
\mathbf{R}, R^{2}, \mathbf{A d j} . R^{2}, \mathbf{F}, \quad \mathbf{D}-\mathbf{W}\end{array}$ \\
\hline Basic competency & Core competency & 0.968 & 0.144 & 2.181 & 0.030 & $.144, .021, .016,4.755,2.066$ \\
\hline Task competency & Core competency & 0.872 & 0.452 & 7.606 & 0.000 & $.452, .205, .201,57.853,2.002$ \\
\hline Leadership & Core competency & 0.926 & 0.321 & 5.092 & 0.000 & $.321, .103, .099,25.925,1.929$ \\
\hline Organization Characteristics & Core competency & 0.912 & 0.362 & 5.828 & 0.000 & $.326, .191, .127,33.961,1.907$ \\
\hline Core competency & Price advantage & 0.672 & 0.501 & 8.680 & 0.000 & $.501, .251, .218,75.341,2.132$ \\
\hline Core competency & Differentiation advantage & 0.572 & 0.765 & 17.823 & 0.000 & $.765, .585, .585,317.669,2.121$ \\
\hline Price advantage & Financial achievement & 0.775 & 0.109 & 1.646 & 0.101 & $.109, .012, .0082 .709,2.474$ \\
\hline Price advantage & Non-financial achievement & 0.776 & 0.015 & 0.221 & 0.825 & $.015, .000,-.004, .029,2.189$ \\
\hline Differentiation advantage & Financial achievement & 0.761 & 0.216 & 3.325 & 0.001 & $.216, .047, .043,11.059,2.250$ \\
\hline Differentiation advantage & Non-financial achievement & 0.672 & 0.501 & 8.680 & 0.000 & $.501, .251, .248,75.341,2.132$ \\
\hline
\end{tabular}

Table 4: Results of Analyzing Mediating Effects of Core Competence_Price Advantage

\begin{tabular}{|c|c|c|c|c|c|}
\hline \multicolumn{2}{|c|}{ Independent Variable } & Dependent Variable & $\beta$ & $\mathrm{t}$-value & signi ficance \\
\hline \multirow{4}{*}{$\begin{array}{c}\text { Basic } \\
\text { Competency }\end{array}$} & Basic Competency & Core Competency & 0.144 & 2.181 & 0.03 \\
\hline & Basic Competency & Price Advantage & 0.431 & 7.159 & 0.000 \\
\hline & Basic Competency & \multirow{2}{*}{ Price Advantage } & 0.418 & 7.028 & 0.000 \\
\hline & Core Competency & & 0.165 & 2.779 & 0.006 \\
\hline \multirow{4}{*}{$\begin{array}{c}\text { Task } \\
\text { Competency }\end{array}$} & Task Competency & Core Competency & 0.452 & 7.606 & 0.000 \\
\hline & Task Competency & Price Advantage & 0.322 & 5.110 & 0.000 \\
\hline & Task Competency & \multirow{2}{*}{ Price Advantage } & 0.199 & 3.055 & 0.003 \\
\hline & Core Competency & & 0.384 & 5.892 & 0.000 \\
\hline \multirow{4}{*}{ Leadership } & Leadership & Core Competency & 0.321 & 5.092 & 0.000 \\
\hline & Leadership & Price Advantage & 0.252 & 3.910 & 0.000 \\
\hline & Leadership & \multirow{2}{*}{ Price Advantage } & 0.261 & 3.818 & 0.000 \\
\hline & Core Competency & & 0.026 & 2.824 & 0.005 \\
\hline \multirow{4}{*}{$\begin{array}{c}\text { Organization } \\
\text { Characteristics }\end{array}$} & Org. Characteristics & Core Competency & 0.362 & 5.838 & 0.000 \\
\hline & Org. Characteristics & Price Advantage & 0.153 & 2.919 & 0.021 \\
\hline & Org. Characteristics & \multirow{2}{*}{ Price Advantage } & 0.202 & 2.911 & 0.004 \\
\hline & Core Competency & & 0.148 & 2.131 & 0.034 \\
\hline
\end{tabular}


Table 5: Results of Analyzing Mediating Effects of Core Competence_Differentiation Advantage

\begin{tabular}{|c|c|c|c|c|c|}
\hline \multicolumn{2}{|c|}{ Independent Variable } & Dependent Variable & $\beta$ & t-value & significance \\
\hline \multirow{4}{*}{$\begin{array}{c}\text { Basic } \\
\text { Competency }\end{array}$} & Basic Competency & Core Competency & 0.144 & 2.181 & 0.030 \\
\hline & Basic Competency & Differentiation Advantage & 0.227 & 3.498 & 0.001 \\
\hline & Basic Competency & \multirow{2}{*}{ Differentiation Advantage } & 0.120 & 2.797 & 0.006 \\
\hline & Core Competency & & 0.748 & 17.501 & 0.000 \\
\hline \multirow{4}{*}{$\begin{array}{c}\text { Task } \\
\text { Competency }\end{array}$} & Task Competency & Core Competency & 0.452 & 7.606 & 0.000 \\
\hline & Task Competency & Differentiation Advantage & 0.507 & 8.813 & 0.000 \\
\hline & Task Competency & \multirow{2}{*}{ Differentiation Advantage } & 0.202 & 4.358 & 0.000 \\
\hline & Core Competency & & 0.674 & 14.549 & 0.000 \\
\hline \multirow{4}{*}{ Leadership } & Leadership & Core Competency & 0.321 & 5.092 & 0.000 \\
\hline & Leadership & Differentiation Advantage & 0.499 & 8.635 & 0.000 \\
\hline & Leadership & \multirow{2}{*}{ Differentiation Advantage } & 0.282 & 6.824 & 0.000 \\
\hline & Core Competency & & 0.674 & 16.314 & 0.000 \\
\hline \multirow{4}{*}{$\begin{array}{c}\text { Organization } \\
\text { Characteristics }\end{array}$} & Org. Characteristics & Core Competency & 0.362 & 5.828 & 0.000 \\
\hline & Org. Characteristics & Differentiation Advantage & 0.467 & 7.919 & 0.000 \\
\hline & Org. Characteristics & \multirow{2}{*}{ Differentiation Advantage } & 0.218 & 4.989 & 0.000 \\
\hline & Core Competency & & 0.686 & 7.667 & 0.000 \\
\hline
\end{tabular}

Table 6: Summary of Control Effect Analyses of CEO Characteristics on Core Competency and Price Advantage

\begin{tabular}{|c|c|c|c|c|c|c|c|c|c|}
\hline \multirow[b]{2}{*}{ Model } & \multirow[b]{2}{*}{$\mathbf{R}$} & \multirow[b]{2}{*}{ R sq. } & \multirow[b]{2}{*}{ Adj. R sq. } & \multirow[b]{2}{*}{ Std. Error } & \multicolumn{5}{|c|}{ Variation of Statistics } \\
\hline & & & & & $\begin{array}{l}\text { Variation of } \\
\text { R-sq. }\end{array}$ & $\begin{array}{c}\text { Variation of } F \\
\text { value }\end{array}$ & df1 & df2 & $\begin{array}{c}\text { Significance Probability } \\
\text { of } F \text { Variation }\end{array}$ \\
\hline 1 & $.198 a$ & .039 & .035 & .751 & .039 & 9.134 & 1 & 225 & .003 \\
\hline 2 & $.270 \mathrm{~b}$ & .073 & .065 & .740 & .034 & 8.196 & 1 & 224 & .005 \\
\hline 3 & $.446 c$ & .199 & .188 & .689 & .126 & 35.072 & 1 & 223 & .000 \\
\hline \multicolumn{10}{|c|}{$\begin{array}{l}\text { a. Independent variable: constant, core competency } \\
\text { b. Independent variable: constant, core competency, price advantage } \\
\text { c. Independent: constant, core competency, price advantage, CEO ch }\end{array}$} \\
\hline
\end{tabular}

Table 7: Summary of Control Effect Analyses of CEO Characteristics on Core Competency and Differentiation Advantage

\begin{tabular}{|c|c|c|c|c|c|c|c|c|c|}
\hline \multirow[b]{2}{*}{ Model } & \multirow[b]{2}{*}{$\mathbf{R}$} & \multirow[b]{2}{*}{ R sq. } & \multirow[b]{2}{*}{ Adj. R sq. } & \multirow[b]{2}{*}{ Std. Error } & \multicolumn{5}{|c|}{ Variation of statistics } \\
\hline & & & & & $\begin{array}{c}\text { Variation of } R \\
\text { sq. }\end{array}$ & $\begin{array}{c}\text { Variation of } \mathrm{F} \\
\text { value }\end{array}$ & df1 & df2 & $\begin{array}{c}\text { Significance Probability } \\
\text { of } F \text { Variation }\end{array}$ \\
\hline 1 & $.528 a$ & .279 & .275 & .754 & .279 & 86.913 & 1 & 225 & .000 \\
\hline 2 & $.599 b$ & .359 & .354 & .712 & .081 & 28.232 & 1 & 224 & .000 \\
\hline 3 & $.601 c$ & .362 & .353 & .713 & .002 & .821 & 1 & 223 & .366 \\
\hline
\end{tabular}

<Table 4>에서 CEO의 독립변수인 기본역량, 직무역량, 리 더십, 그리고 조직특성이 가격우위 전략에 영향을 미치는 과정 에서 핵심역량이 매개효과를 가지고 있다는 것을 알 수 있다. 다음은 독립변수인 $\mathrm{CEO}$ 의 기존역량, 직무역량, 리더십, 조직 특성이 차별화전략에 영향을 미치는 과정에서 핵심역량이 매 개효과를 갖는지 여부에 대한 분석 결과이다.

<Table 5>에서 $\mathrm{CEO}$ 의 독립변수인 기본역량, 직무역량, 리 더십, 그리고 조직특성이 차별화 전략에 영향을 미치는 과정에 서 핵심역량이 매개효과를 가지고 있다는 것을 알 수 있다.

\section{4. 조절효과 분석}

5.4.1. 핵심역량이 가격우위에 영향을 미치는 과정에 기업특 성이 조절효과를 갖는지 여부

핵심역량이 가격우위 전략에 영향을 미치는 과정에서 기업
특성 중 $\mathrm{CEO}$ 가 전문지식 혹은 기술을 보유가 조절효과를 분 석해 보았으며 그 결과는 <Table 6>에 요약되어 있다.

조절효과 판정은 설명력 $\left(R^{2}\right)$ 이 유의수준 하에서 유의하게 증가하였는지 여부에 따라 결정한다(Song, 2014). <Table 6> 에서 설명력이 모델 속에 독립변수, 조절변수가 포함될수록 증 가하고 있으며, 증가가 유의한 수준에서 증가했는지를 나타내 는 F값의 변화 역시 유의하다고 나타나고 있다. 따라서 핵심 역량이 가격우위 전략에 영향을 미치는 과정에서 CEO특성이 조절효과를 갖는다고 판정한다.

5.4.2. 핵심역량이 차별화우위에 영향을 미치는 과정에 기업 특성이 조절효과를 갖는지 여부

다음으로 핵심역량이 차별화우위 전략에 영향을 미치는 과 정에서 $\mathrm{CEO}$ 특성이 조절효과를 갖는지 여부에 대한 분석결과 는 <Table 7>에 요약되어 있다. 
<Table 7>에서 F변화가 유의한 수준에서 증가하고 있지 않 다는 것을 알 수 있고 따라서 CEO특성이 조절효과를 갖지 않 는다고 판정한다.

\section{6. 결론}

\section{1. 연구목적}

중소기업 그 중에서도 특히 제조기업은 국가 산업의 한 축 이며 고용을 짊어지고 있는 국가산업의 근간이라고 해도 과언 이 아니다. 이러한 차원에서 중소 제조기업에 대한 지원정책이 마련되어 실시되는 등 관심과 지원이 대두되고 있으나 현실적 으로 이에 대한 연구는 찾아보기 힘든 것이 사실이다. 그것은 중소제조기업의 사업범위가 다양하여 공통된 이슈를 찾기 힘 든 점, 외부 감사를 받는 등으로 인하여 기업실적 등이 외부로 공식적으로 공개되는 경우가 많지 않아 자료를 수집하기 어려 운 점 등으로 인한 것으로 생각된다.

중소제조기업의 경우 기업의 $\mathrm{CEO}$ 가 기업의 존망에 핵심적 역할을 한다는 점에 대한 일반적 공감은 형성되어 있어 CEO 의 특성, 역할, 역량 등에 대한 연구는 꾸준히 수행되어 왔다. 그리하여 $\mathrm{CEO}$ 의 특성, 역량이 기업성과에 미치는 영향에 대 한 연구는 수행되어 왔으나, 특성 혹은 역량과 성과간의 연관 관계를 살펴보는 수준에 머무르고 있는 것이 사실이다. 이에 본 연구에서는 중소제조기업의 $\mathrm{CEO}$ 의 역량, 기업의 조직특성 등 자원이 핵심역량을 이루고 이를 기반으로 한 경쟁우위를 마련하여 경영성과로 이어지는 과정을 분석해 보았다.

\section{2. 연구방법}

연구는 경기도 인근 중소제조기업 $\mathrm{CEO}$ 들을 대상으로 직접 방문을 하고 설문조사를 실시하였다. 설문의 내용은 중소제조 기업의 존립을 좌우한다고 볼 수 있는 $\mathrm{CEO}$ 의 특성에 대한 부 분, 기업의 조직적 특성에 대한 사항, 핵심역량, 기업의 전략 적 차별화, 그리고 경영성과에 대한 것이다. 특별히 중점을 둔 부분은 $\mathrm{CEO}$ 의 역량 중 개인특성적 역량과 직무에 관한 역량 그리고 리더십에 대한 설문을 통한 자료수집이며, 이러한 특성 이 어떻게 핵심역량으로 전환되어 경쟁력을 형성하며, 차별화 등을 통한 기업의 존속과 수익창출로 이어지도록 하는지에 대 한 분석이다.

\section{3. 연구결과}

연구결과로 대부분의 선행연구들과 마찬가지로 $\mathrm{CEO}$ 의 심 리적 특성, 인성적 특성을 반영하는 기본적 역량, 정보취득 능 력, 관리능력, 산업에 대한 이해 등 직무 관련 역량, 조직내 리더십과 조직특성이 기업의 핵심역량에 유의한 영향을 미치 는 것으로 나타나고 있다. 핵심역량은 다시 가격우위와 차별화 우위에 유의한 양(+)의 영향을 미친다는 결과를 얻고 있다. 그 러나 가격우위는 재무적 성과는 물론 비재무적 성과에 유의한 영향을 미치지 않는 것으로 나타나고 있다. 반면, 차별화우위 는 재무적 성과와 비재무적 성과 모두에게 유의한 영향을 미 치는 것으로 나타나고 있다. 한편, 핵심역량이 가격우위 혹은 차별화우위로 진행하는 과정에서 $\mathrm{CEO}$ 의 해당 분야 지식 혹은
기술보유 유무로 측정된 기업특성이 조절효과를 갖는지 여부 에 대한 분석결과 가격우위에는 조절효과를 갖는 것으로 나타 나고 있으나 차별화우위에는 조절효과가 없는 결과를 보이고 있다. 이러한 결과는 중소제조기업 CEO가 해당 분야에 대한 기술이나 전문지식을 보유하고 있을 경우 기술력을 바탕으로 한 가격경쟁력을 높이는 전략을 주로 구사한다고 해석할 수 있으며, 특히 중소제조업 분야의 경우 거래상대방이 서로 오랜 시간 동안 관계를 맺어온 경우가 많을 것이어서 새로운 기술 이나 디자인이 요구된다기 보다 원가절감을 통한 이윤추구가 서로 간에 더 큰 이익을 가져다준다고 생각할 수 있다.

문제는 가격우위가 재무적 및 비재무적 성과로 이어지고 있지 않다는 연구결과이다. 이러한 결과의 시사점은 중소제조 기업이 단순히 가격경쟁력만을 추구하기 보다는 급격히 변하 는 산업환경에 대한 발 빠른 이해와 대처로 신상품이나 디자 인 개발, 고객수요에 대한 선제적 파악, 내부고객의 만족도 증 가 및 역량 증진 등을 통한 전사적 경쟁력 제고가 필요하다는 점이 중요하다는 인식이 필요하다는 것이다.

\section{4. 구결과의 기여}

본 연구는 중소 제조기업에 대한 연구라는 점, 그리고 가장 핵심적인 $\mathrm{CEO}$ 의 역량에 대한 연구라는 점, 그리고 선행 연구 와 다르게 이러한 역량이 기업성과에 미치는 영향을 바로 분 석한 것이 아니고 이를 세부적으로 구분하여 분석하였다는 점 등이다. 대기업의 경우 인적자원에 기초하거나 조직력에 기한 정밀한 시장분이 가능하고 그 결과에 대한 대처를 지속적이고 체계적으로 수행할 수 있을 것이란 점, 기술력과 R\&D능력에 기한 신상품개발과 원가절감 등 생산성 향상이 가능 할 것이 지만 중소기업 특히 제조업의 경우 $\mathrm{CEO}$ 의 기술력 혹은 역량 에 의존하는 경향이 크다. 문제는 이러한 특성이 지속가능성이 나 성장성에 기여할 수 있도록 작동하지 못할 수 있다는 점이 다. 그리하여 정부차원에서의 중소제조기업 지원 등 정책을 펴 는데 있어 $\mathrm{CEO}$ 의 기술력 보유 여부, 역량에 따른 차별적이고 체계적인 지원과 교육이 필요할 것이라 판단된다.

\section{References}

Barton, Leonard, D. (1992). Core capabilities and core rigidities: A paradox in managing new product development. Strategic management journal, 13(S1), 111-125.

Beard, D. W., \& Dess, G. G. (1981). Corporate-level strategy, business-level strategy, and firm performance. Academy of Management Journal, 24(4), 663-688.

Chang, S. J. (2007). Global Strategic Management in the age of global competition. Pakyoung Publishing co.

Choi, B. G. (2008). Managing Firm Resources to Create Value: Based on ERP Implementation, Information Systems Review, 10(3), 111-132.

Choi, K. K., \& Kim, S. K. (2005). The Effect on the Job Performance of the ERP Introduction in SMEs. Small and medium-sized research, 27(4), 29-53.

Choo, S. Y., Yoo, J. M., \& Lim, S. J. (2009). A Study on 
the Effects of the Fit among Environment, Strategy and Competence on Firm Performance. Strategic Management Research, 12(1): 101-126.

Collis, D. J., \& Montgomery C. 1995. Competing on resources: strategy in the 1990s. Harvard Business Review, 73(4), 118-128.

Conant, J. S., Mokwa, M. P., \& Varadarajan, P. R. (1990). Strategic types, distinctive marketing competencies and organizational performance: A multiple measures-based study. Strategic Management Journal, 11(2), 365-383.

Dierickx, I., \& Cool, K. (1989). ASSET STOCK ACCUMULATION AND THE SUSTAINABILITY OF COMPETITIVE ADVANTAGE: REPLY. Management Science, 35(12).

Ghemawat, P. (2009). Strategy and the Business Landscape. New York: Prentice Hall.

Goo, J. D. (2009). A Study on the Relationship among Core Competence, Non-Financial and Financial Management Performances of Hotel Industry. International Journal of Tourism Management and Sciences, 23(4): 259-277.

Grant, R. M. (1991). The Resource-Based Theory of Competitive Advantage: Implications for Strategy Formulation. California Management Review, 33(3), 114-135.

Gupta, A. K. (1987). SBU strategies, Corporate-SBU Relations, and SBU Effectiveness in Strategy Implementation. The Academy of Management Journal, 30(3), 477-500.

Gwak, G. Y., Choi, J. S., \& Baek, G. B. (2016). The Moderating Effect of CEO Competency in the Relations between SME CEO's Issue Leadership and SME Performance, Korea Business Journal, 29(2), 195-212

Han, H. J., \& Yoon, S. M. (2011). A Study on the Influence of Corporate Culture on Financial Performance: Focusing on Hotel Corporate Culture and Perceived Performance. Hotel Management Research, 20(1), 267-284.

Hitt, M. A., \& Ireland, R. D. (1986). Relationships among corporate level distinctive competencies, diversification strategy, corporate structure and performance. Journal of management studies, 23(4), 401-416.

Jeon, J. Y. (2011). A Study on the Effects of Family Restaurant's Core Competency on the Organizational Effectiveness. Ph.D Dissertation, King Sejong University.

Jung, D. Y. (2008). The Hierarchical Linear Relationship among Career Commitment, Individual Characteristics and Organizational Characteristics of High School Graduate Early Careers in Small and Medium Enterprises. Ph. D. Dissertation. Education in the Graduate School, Seoul National University.

Jung, D. Y., \& Eom, T. Y. (2010). A Study on the Effects of First Mover Advantage and Competitive
Advantage on Firm Performance in the Franchise Industry. Korea Business Administration Society, Working Paper, 1-19.

Jung, D. Y., \& Yang, C. H. (2008). The Effects of Core Competence and Networking on Firm Performance Comparative study between Korea and China SMEs. Journal of the Korean Entrepreneurship Society, 3(2), 43-69.

Jung, D. Y., \& Yang, C. H. (2009). An Empirical and Comparative Study of Modeling the Relationship between Networking and Perceived Firm Performance of SMEs of Korea and China. International Business Review, 13(2), 27-56.

Kang, S. M., \& Lee, H. T. (2012). A Study on the Effects of Entrepreneurship and Core Competencies on Firm Performance. Journal of Marketing Studies, 20(1), 1-16.

Kim, E. H. (2002). Competition Strategy based on the Management Resource Theory, Koreanische Zeitschrift fuer Wirtschaftswissenschaften, 20(2): 65-82.

Kwan, K. H. (2006). Conceptual evolution within the modern resource-based view: An assessment and review. Korea Business Review, 9(2), 215-244.

Kwan, Y. C. (2010). Dynamic Capabilities of Multinational Subsidiaries: Determinants and Performance. Management Review, 39(5), 1151-1175.

Kwon O. I., \& Lee, G. D. (2007). Exploratory consideration of the relationship between small and medium-sized businesses, CEOs, Strategies, HRM, and the impact of consistency on performance, Conference of Korea integrated academic publication Proceedings, $1-19$,

Kim, C. G. (2005). Core Competences for Sustaining Competitive Advantage. Community Development Review, 5(1), 265-278.

Kim, M. K. (2002). A Study on the Determinants of Leverage in Unlisted Small and Medium Enterprises. The Korean journal of financial management, 19(1), 33-66.

Lee, J. H., \& Kim, Y. U. (2003). Effects of Technological Capability, Owners' Characteristics, and Organizational Structures on Financial Performance. Small and Medium Business Research, 25(4), 79-111.

Lucia, A. D., \& Lepsinger, R. (1999). The art and science of competency models: Pinpointing critical success factors in organizations. New York, NY: Pfeiffer.

Mahoney, J. T. (1995). The management of resources and the resource of management. Journal of business research, 33(2), 91-101.

Makadok, R. (2001). Toward a Synthesis of the Resources-Based and Dynamic-Capability Views of Rent Creation. Strategic Management Journal, 22, 387-401.

Nam, O. J., \& Lee, C. S. (2009). The Mediating Effect of Management Strategy on the Relationship of Internal 
Marketing and Performance of Hotel Corporations. Hotel Management Research, 18(3), 99-118.

Noh, H. J. (2012). A Study on the Effect of Core Competencies and Value Innovation Strategies on Business Performance in the Manufacturing Industries. Korea Computer Information Society Journal, 17(4), 155-161.

Park, C. M. (2005). The Impact of the Firm Performance on the SMEs CEO Characteristics in Yeongnam Area, Industrial and Economic Studies, 18(3), 1075-1101.

Park, G. S., Choi, S. C., \& Park, H. B. (2008). The study on the strategic resource effect on performance measure and firm's performance. Journal of Tax and Accounting, 22, 75-94.

Park, J. H., Hur, J., \& Keum, S. B. (2011). A Study on Management Performance of Food Manufactory Companies for Traceability System. Food Management Research, 14(1), 47-65.

Park, S. H., Cho, N. J., \& Kang, T. G. (2004). The Effect of Competitive Strategy and Information Intensity on the Usage of Information \& Communication Technology. Journal of Korea Industrial Economics, 17(4), 1485-1508.

Park, S. Y., \& Lee, C. (2011). Development of a Competency Model for CEO in SMEs. Journal of agricultural education and human resource development, 43(1), 87-106.

Park, W. S. (2002). Human Resource Management by Capabilities. Working Paper, Korea Labor Research Institute.

Porter, M. E. (1980). Competitive strategy. New York: Free Press.
Porter, M. E. (1990). The Competitive Advantage of Nations. New York: Free Press.

Seo, K. H. \& Lee, S. B. (2011). The Effect of Corporate Image on the Service Quality, Fitness of Extension Brand and Attitude: Focus on Food Service Corporate. Journal of Korea Food and Cooking, 20(59), 69-92.

Seo, K. H., \& Lee, S. B. (2012). The Effect of Managerial Resources of Food Service Enterprises on Competition Strategy and Business Performance. Tourism Research Journal, 26(2), 279-296.

Shin, J. K. (2008). The Organizational Characteristics And Technology Commercialization Of SMEs - Moderating Effects Of Internal Integration And External Network -. Journal of Human Resource Management Research, 15(2), 159-175.

Son, E. H., \& Kim, K. H. (2007). Effects of the Alignment between Core Competence and competitive Strategy on the Business Performance in the Hotel Industry. Journal of Hotel Management, 16(4), 93-111.

Son E. H., \& Kim, K. H. (2007). Effects of the Alignment between Core Competence and Competitive Strategy on the Business Performance in the Hotel Industry. Hotel Management Review, 16(5), 93-111.

Teece, D. J., Gary Pisano, \& Amy Shuen. (1997). Dynamic Capabilities and Strategic Management. Strategic Management Journal, 18, 509-533.

Venkatraman, N., \& Ramanujam, V. (1986). Measurement of Business Performance in Strategy Research: A Comparison of Approaches. Academy of Management Review, 11(4), 801-814.

Wernerfelt, B. (1984). A resource-based view of the firm. Strategic management journal, 5(2), 171-180. 